\title{
A refined dilution technique for measuring the community grazing impact of microzooplankton, with experimental tests in the central equatorial Pacific
}

\author{
M. R. Landry, J. Kirshtein, J. Constantinou \\ Department of Oceanography, University of Hawaii at Manoa 1000 Pope Road, Honolulu, Hawaii 96822, USA
}

\begin{abstract}
The standard dilution technique can provide unbiased estimates of phytoplankton growth and microzooplankton grazing rates only when certain restrictive assumptions are met. The most important of these assumptions - that grazing impact varies in direct proportion to the dilution of grazer population density - can be easily violated when clearance rate of individual grazers and/or growth response of the grazer population vary significantly with food concentration over the course of the incubation. We have developed a modified protocol which now allows the dilution technique to be applied unambiguously, even when its original assumptions may be violated. The new protocol uses flow-cytometry measured disappearance of fluorescently labeled tracer cells (FLB or FLA) as an internal measure of 'relative grazing activity' in each dilution treatment. Coefficients of phytoplankton growth and mortality rates are determined from Model Il regression analyses of 'net growth' versus 'relative grazing', rather than the usual Model I regressions of 'net growth' versus 'dilution factor'. Tests of this hybrid experimental design in the central equatorial Pacific during an EQPAC cruise in August 1992 gave results essentially identical to the standard dilution interpretation.
\end{abstract}

KEY WORDS: Microzooplankton grazing - Flow-cytometry - FLB - Dilution - Synechococcus spp. Prochlorococcus spp. Equatorial Pacific

\section{INTRODUCTION}

In the decade since its introduction, the dilution approach (Landry \& Hassett 1982) has been broadly applied in aquatic ecosystems as a field technique for estimating the growth rate of phytoplankton and the grazing impact of microzooplankton (e.g. Landry et al. 1984, 1993, Campbell \& Carpenter 1986, Burkill et al. 1987, Paranjape 1987, 1990, Gifford 1988, Gallegos 1989, Weisse \& Scheffel-Möser 1990, Andersen et al. 1991, Strom \& Welschmeyer 1991). Nonetheless, as is normal for an experimental method, increasing use has also brought closer scrutiny and critical review. Critiques of the dilution approach have generally addressed specific aspects of experimental design and have been useful in improving protocols and interpretations as the method has evolved (e.g. Fuhrman \& Bell 1985, Li \& Dickie 1985, Gallegos 1989, Li 1990). The more recent critique of Evans \& Paranjape (1992), however, correctly questions the fundamental assumptions and theoretical construct of the technique.
The purpose of the present paper is not to defend the use of the dilution technique under all environmental circumstances. Rather, our response to the theoretical arguments of Evans \& Paranjape (1992) comes in a practical form - a modified experimental approach which can be used to test and validate the critical assumptions of the method with each new application. We present a brief overview of the uncertainties in the dilution technique and an experimental design to address problem areas which have heretofore resisted critical examination. This newly defined protocol is then applied in experimental studies in surface waters of the central equatorial Pacific. In this environment, at least, the assumptions of the dilution technique appear to hold.

\section{THEORY}

\section{Problem statement}

The dilution technique uses incubations of water samples diluted to different degrees with particle- 
free water to uncouple rate estimates of phytoplankton growth and microzooplankton grazing. Each sample yields an independent estimate of the net instantaneous rate of phytoplankton growth measured from the observed change in bulk chlorophyll, taxa-specific pigments or population counts over the incubation period. These net growth estimates $\left(k_{i}\right)$ are related to one another by 2 assumptions (Landry \& Hassett 1982). First, phytoplankton growth rate $(\mu)$ is assumed to be independent of the dilution effect on population density. Second, the rate of phytoplankton mortality $(m)$ due to microzooplankton grazing is assumed to be proportional to the dilution effect on grazer abundance $\left(D_{i}=\right.$ the ratio of abundance in a dilution treatment relative to the abundance in undiluted water). Thus, in the context of the exponential model of population growth,

$$
k_{1}=\mu-\left(m \times D_{j}\right)
$$

In principle, the relationship between net growth rate $\left(k_{1}\right)$ and the dilution factor $\left(D_{1}\right)$ for a group of incubated samples can be solved by linear regression analysis for the instantaneous rate of phytoplankton growth ( $\mu=y$-axis intercept) and grazing mortality ( $m=$ slope).

The first assumption has not been difficult to test or control for in practice. Chavez et al. (1991) found, for example, that the relationship between ${ }^{14} \mathrm{C}$-primary production and mean chlorophyll concentration was unaffected by dilution in nutrient-rich waters of the central equatorial Pacific. In waters where nutrient limitation is perceived to be a problem, constant phytoplankton growth can be maintained by routinely providing an appropriate mixture of inorganic nutrients to each of the dilution treatments. In such cases, the $y$-intercept of the dilution regression may not yield the true phytoplankton growth rate. As further discussed below, however, the actual rate of phytoplankton growth can be estimated by comparing the observed rates of growth in undiluted samples with and without nutrient amendments (e.g. Andersen et al. 1991).

In contrast to the growth rate assumption, the notion that grazing rate varies in direct proportion to dilution is problematic both in theory and testing. Two potential sources of error complicate this assumption. First, differences in the relative densities of grazers established in the initial dilution treatments are unlikely to be exactly maintained throughout the experiment. Flagellated and ciliated protists, which comprise the most abundant and active component of the microzooplankton, have high growth potentials and are likely to be responsive to differences in available food density over the time scales of experimental incubations, which may last a day or more. Thus, initial differences in microzooplankton population den- sities should increase with time as consumers with higher food concentrations (i.e. undiluted samples) grow at faster rates. This growth trend may be confounded, however, by the complexities of trophic interactions in the microbial food web. For example, consumers that occupy intermediate trophic levels (e.g. flagellates) in the contained water samples experience both higher food levels (picoplankton) and higher predator densities (ciliates) in the undiluted samples and, depending on the balance of these factors, may either grow at a faster or slower rate in undiluted relative to more diluted treatments. As noted by Landry (1993), most applications of the dilution technique have not accounted for change in the relative densities of grazers in the treatments. This is difficult, if not impossible, to accomplish in routine practice. Not only are the required microscopical analyses laborious and imprecise, unless all of the component microzooplankton populations vary in exactly the same way among dilution treatments, it will not be easy to relate observed differences in the rates of change of the various consumer populations to their equivalencies in terms of total community grazing impact on phytoplankton.

Even if the initial dilution effect on microzooplankton population densities could be perfectly maintained during experimental incubations, the functional response relationship between the clearance rates of individual grazers and food concentration would have to be taken into account. As presently interpreted, the dilution approach assumes that individual clearance rates of microzooplankton are constant, i.e. independent of the dilution effect on food concentration. At best, this assumption can only be true under circumstances in which the natural food density is below the level that saturates ingestion rates and the lowest concentration in diluted samples is above the density that elicits threshold feeding behavior. Gallegos (1989) demonstrated that the normal analytical framework for the dilution approach had to be modified to account for saturated feeding in a eutrophic river system. The critique of Evans \& Paranjape (1992) generalized this result. Given all of the possible curvilinear models that might define relationships between feeding rate and food concentration for given groups or species of consumers or the microzooplankton as a whole, it would seem improbable that the linear model (constant clearance rate) would be the best assumption under most, if any, circumstances. By restricting analyses of dilution results to the linear regression model, therefore, the method implicitly understates the range of phytoplankton growth and microzooplankton grazing rate estimates that would be achieved using any one of a number of equally likely analytical schemes 


\section{An enhanced experimental protocol}

In light of the problems mentioned above, it is important to recognize that 'dilution factor' $\left(D_{i}\right)$ is used in regression analyses of dilution experiments only as a proxy for the actual parameter of interest, which is the relative grazing activity of microzooplankton. That is to say, if an independent estimate of the relative microzooplankton grazing replaced $D_{1}$ in Eq. (1), the regression analysis would no longer depend on the potentially unrealistic assumption that grazing activity is directly proportional to the dilution effect on population density. In regions of the ocean dominated by autotrophic picoplankton, fluorescently labeled bacteria (FLB) of an appropriate size can be used in tracer concentrations to provide such an independent estimate of microzooplankton grazing activity. The disappearance of these FLB during experimental incubations can give an index of grazing activity in each of the dilution treatments that integrates all of the factors affecting individual clearance rates and population densities of the microzooplankton over the course of the experimental incubation.

An idealized interpretation of a dilution experiment incorporating both nutrient enrichment of phytoplankton growth and an independent assessment of relative grazing activity is presented in Fig. 1. Instantaneous growth rate $\left(\mu_{n}\right)$ is assumed to be identical for all treatments with added nutrients allowing the rate of grazing mortality $(m)$ to be calculated from the regression relationship between net phytoplankton growth rate (with nutrients) and relative grazing. This mor-

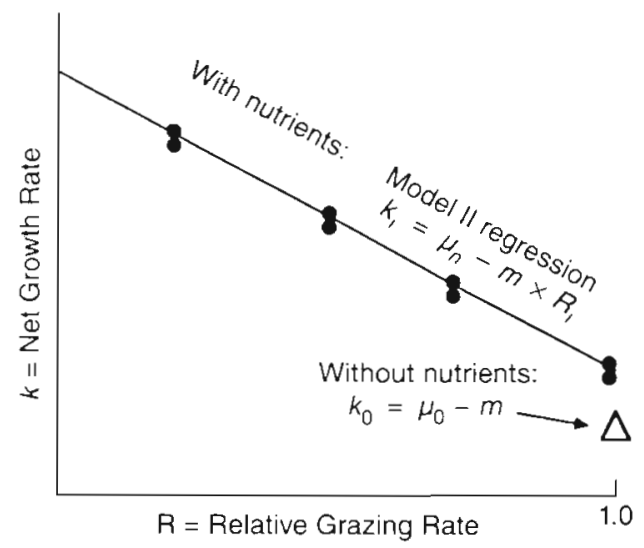

Fig. 1. Interpretation of an idealized dilution experiment incorporating incubations with $(\bullet)$ and without $(\Delta)$ nutrient additions and an independent measure of relative grazing activity. $k$ : observed net growth of phytoplankton; $\mu_{n}$ : instantaneous rate of phytoplankton growth with added nutrients; $\mu_{0}$ : phytoplankton growth rate without added nutrients; $m$ : phytoplankton mortality attributable to microzooplankton grazers; $R$ : relative grazing activity estimated from disappearance of fluorescently labeled tracer cells and normalized to the mean rate observed in incubated samples of undiluted water tality estimate can then be used with the net growth rate in samples incubated without added nutrients to determine the instantaneous growth rate of phytoplankton $\left(\mu_{0}\right)$ without nutrient amendment. The ratio $\mu_{0}: \mu_{n}$ indicates whether and/or to what extent growth is limited by nutrient availability. In addition, FLB disappearance in incubated samples with and without nutrients provides a cross-check to insure that nutrient amendments do not significantly affect microzooplankton grazing rates.

One additional factor that must be considered in using the experimental design is the choice of an appropriate regression model. As noted by Laws \& Archie (1981; see also Ricker 1973), the standard Model I technique requires, among other things, that the independent ( $x$-axis) variable be under investigator control. To our knowledge, Model I theory has been applied exclusively in the analyses of dilution experiments to date. This seems appropriate for the most part, since the level of dilution can be controlled within reasonable limits. The situation can be ambiguous, however, when $D_{i}$ is a measured variable (e.g. the ratio of chlorophyll in diluted treatments relative to undiluted natural water) or if $D_{i}$ is subsequently corrected for changes in micrograzer population density. Nonetheless, if the independent variable is an experimentally measured rate estimate of relative grazing, Model II regression analysis is required.

\section{MATERIALS AND METHODS}

Dilution experiments were conducted in the central equatorial Pacific as part of the JGOFS (Joint Global Oceans Flux Studies) EQPAC Program along longitude $140^{\circ} \mathrm{W}$ in August-September 1992. A subset of 5 experiments were chosen for detailed analysis to demonstrate the operating principles of the modified approach and for comparison with the standard analytical procedure. These include replicate experiments with near-surface water $(10 \mathrm{~m})$ at the equator, 1 experiment from deeper in the equatorial mixed layer $(40 \mathrm{~m})$, and experiments using $10 \mathrm{~m}$ water from $1^{\circ} \mathrm{N}$ and $1^{\circ} \mathrm{S}$ (Table 1 ).

Experimental setup. All containers, tubing (silicone) and transfer apparatus were precleaned by a modified version of the Fitzwater et al. (1982) protocol consisting of sequential overnight soaks in Micro detergent-deionized water, 10\% $\mathrm{HCl}-\mathrm{Milli} \mathrm{Q}$ water (2 times), $2 \%$ nitric acid-Milli $Q$ water, and 3 rinses with quartz-distilled water. Incubation bottles and tubing were soaked between uses in 10\% $\mathrm{HCl}-\mathrm{Nan}$ opure water and rinsed 3 times with Nanopure water and finally with filtered seawater. Plastic gloves were worn during all phases of experimental set-up, subsampling, and cleaning. 
Table 1. Locations, dates, times and depths at which water samples were collected, and incubation conditions for selected dilution experiments conducted in the central equatorial Pacific during August 1992. Chlo: initial chlorophyll concentration; \% $\mathrm{I}_{0}$ : light intensity during shipboard incubation. All experiments were incubated for $24 \mathrm{~h}$

\begin{tabular}{|ccccccc|}
\hline $\begin{array}{c}\text { Experi- } \\
\text { ment }\end{array}$ & Location & Date & Time & $\begin{array}{c}\text { Depth } \\
(\mathrm{m})\end{array}$ & $\begin{array}{c}\mathrm{Ch}_{0} \\
\left(\mu \mathrm{fl}^{-1}\right)\end{array}$ & $\% \mathrm{I}_{0}$ \\
\hline $7 \mathrm{~A}$ & $1^{\circ} \mathrm{N}, 140^{\circ} \mathrm{W}$ & $27 \mathrm{Aug}$ & $02: 30$ & 10 & 0.341 & $50 \%$ \\
$8 \mathrm{~A}$ & $0^{\circ}, 140^{\circ} \mathrm{W}$ & $28 \mathrm{Aug}$ & $21: 50$ & 10 & 0.340 & $50 \%$ \\
$8 \mathrm{~B}$ & $0^{\circ}, \quad 140^{\circ} \mathrm{W}$ & $28 \mathrm{Aug}$ & $21: 50$ & 40 & 0.461 & $14 \%$ \\
$8 \mathrm{D}$ & $0^{\circ}, 140^{\circ} \mathrm{W}$ & $29 \mathrm{Aug}$ & $17: 00$ & 10 & 0.283 & $50 \%$ \\
$9 \mathrm{~A}$ & $1^{\circ} \mathrm{S}, 140^{\circ} \mathrm{W}$ & $31 \mathrm{Aug}$ & $20: 40$ & 10 & 0.208 & $50 \%$ \\
\hline
\end{tabular}

through a $2 \mu \mathrm{m}$ filter to remove clumps before experiments. Each bottle was injected with trace densities of FLB (final concentration $5 x$ $10^{3}$ cells $\mathrm{ml}^{-1}$ ) during the filling procedure. After initial subsampling experimental bottles were tightly capped and incubated in shipboard incubators for $24 \mathrm{~h}$ under ambient temperature and simulated (neutral density screening) in situ light conditions.

Subsampling and sample analyses. Initial and final subsamples were taken for chlorophyll and flow cytometric analyses (FCM). Replicate chlorophyll samples $(280 \mathrm{ml})$ were taken from the 3 'initial' bottles and from the filtered seawater carboy at the start of an

Seawater was collected in $30 \mathrm{I}$ Go-Flo bottles with teflon lining mounted on a custom-made, trace metalfree rosette. Seawater was gravity filtered directly from the Go-Flo bottles to clean carboys via a closed system consisting of silicone tubing and an in-line, $0.2 \mu \mathrm{m}$ Suporcap (Gelman) filter. New filter capsules were prepared for each experiment by soaking for at least $2 \mathrm{~h}$ in $10 \% \mathrm{HCl}-\mathrm{Nanopure}$ water and rinsing with Nanopure water. In addition, the first several liters filtered through each new filter were discarded.

Each experiment was set up in fourteen $2.7 \mathrm{l}$ polycarbonate bottles. In each experiment, 8 of the bottles were used for the nutrient-enriched dilution series. Filtered seawater was added by volume to replicate bottles to achieve final plankton densities of about 20 , 45, 70 and $100 \%$ ambient levels. Each bottle in the dilution series received an amendment of nutrients [final concentrations: $0.5 \mu \mathrm{M} \mathrm{N}$-ammonium, $0.03 \mu \mathrm{M}$ phosphate, $1 \mathrm{nM}$ iron $\left(\mathrm{FeSO}_{4}\right)$, and $0.1 \mathrm{nM}$ manganese $\left.\left(\mathrm{MnSO}_{4}\right)\right]$ prior to the filling operation. Of the remaining 6 bottles, 1 was filled with filtered seawater and run as a control to account for organisms that passed through the filter (e.g. Li 1990) and 5 were filled without nutrient enrichment -2 to be incubated as natural seawater controls and 3 to be sacrificed for initial samples.

Unfiltered seawater was added to the experimental bottles from the Go-Flo bottles by silicone tubing which reached to the bottom of the incubation bottles to avoid damaging the grazers during transfer. Appropriate precautions were taken to avoid contaminating no-nutrient treatments with the nutrient-enriched water from the dilution series

FLB were prepared in the laboratory before the cruise according to the protocol of Sherr et al. (1987). Vibrio damsella was used because of its relatively uniform coccoid shape $(1.1 \mu \mathrm{m}$ diameter $)$. Aliquots of the prepared FLB were quick frozen in quantities appropriate for daily use at sea. These aliquots were thawed, diluted, sonicated and vortexed briefly, and filtered experiment and from all of the 11 remaining bottles at the end. One FCM subsample $(3 \mathrm{ml})$ was taken from each of the bottles initially, and replicate subsamples were taken at the end of the incubation.

Chlorophyll samples were filtered onto $24 \mathrm{~mm} \mathrm{GF} / \mathrm{F}$ glass-fiber filters and extracted in $10 \mathrm{ml}$ of $90 \%$ acetone for $24 \mathrm{~h}$ at $-20^{\circ} \mathrm{C}$. Chlorophyli concentration was measured fluorometrically with a Turner Designs fluorometer. The equations for fluorometric chlorophyll determination were calibrated by HPLC, and results were strongly correlated with HPLC-determined chlorophyll a $\left(r^{2}=0.97\right.$, R. Bidigare pers. comm.).

FCM samples were preserved with final concentrations of $0.9 \%$ paraformaldehyde, which was filtered $(\mathrm{GF} / \mathrm{F})$ and adjusted to $\mathrm{pH} 7.4$ before each use. These samples were frozen in liquid nitrogen and stored at $-85^{\circ} \mathrm{C}$. Thawed samples were stained with Hoechst 33342 (0.8 $\mathrm{kg} \mathrm{ml}^{-1}$, Molecular Probes) for $1 \mathrm{~h}$ prior to being analysed for population abundance of phytoplankton and FLB using a Coulter EPICS 753 flow cytometer with dual lasers (Monger \& Landry 1993). Prochlorococcus spp. and Synechococcus spp. populations were distinguished from nonpigmented picoplankton by their respective red (divinyl chlorophyll) and orange (phycobilin) autofluorescences under $488 \mathrm{~nm}$ excitation. FLB were characterized by bright green fluorescence (DTAF stain). Eukaryotic nanoplankton had higher red (chlorophyll) and blue (DNA content; UV excitation) fluorescence per cell and larger size (right angle light scatter) than the prokaryotic picoplankton.

Data analyses. Net rates of change $\left(k_{i}, \mathrm{~d}^{-1}\right)$ of measured variables (total chlorophyll, Prochlorococcus spp., Synechococcus spp., nanoeukaryotes, and FLB) were determined from initial parameters $\left(P_{0}\right)$ and final $\left(P_{t}\right)$ estimates assuming an exponential model

$$
k_{1}=\frac{1}{t} \ln \frac{P_{t}}{P_{0}}
$$

where $t$ is the duration of the experiment (1 d). We 
determined if the desired (i.e. investigator-controlled) level of dilution (i.e. $D_{l}$ ) was achieved by comparing initial FCM population estimates of Prochlorococcus spp. or Synechococcus spp. (Expt 8A) from dilution treatments to those in undiluted samples. Population densities in the filtered water were insignificant (mean $=0.7 \%$ of natural Prochlorococcus spp. cell densities, range $=0.5$ to $0.9 \%$ ). Relative grazing activity was determined from the ratio of the instantaneous rates of disappearance of FLB in diluted bottles relative to those in undiluted bottles.

For each experiment and each variable measured, we computed estimates of phytoplankton growth rate and microzooplankton grazing impact by 2 methods the standard approach based on $D_{1}$ and the refined approach using 'relative grazing' as the $x$-axis variable. In both cases, only results from the 8 bottles (dilution series) with added nutrients were used in the regression analyses. As in Fig. 1, growth rate without added nutrients was computed from the mortality estimate provided by the regression analysis and the mean observed net rate of phytoplankton growth in bottles without added nutrients.

Model I regression theory (Sokal \& Rohlf 1981) was used to compute growth and mortality estimates from net growth and dilution factor. Model II theory (geometric mean, reduced major axis) was applied to regressions involving experimentally derived estimates of relative grazing. For these applications, regression slopes were determined according to Ricker (1973) and standard deviations of the slopes and $y$-intercepts were based on York (1966). Confidence limits of the Model II rate estimates were computed according to Jolicoeur \& Moismann (1968).

\section{RESULTS}

FCM analyses of picoplankton abundance and FLB disappearance were used to determine initial dilution factors and relative grazing activities for each of the 8 dilution bottles in the 5 experiments. As might be hoped, a significant $(\mathrm{p}<0.05)$ and positive correlation was found between these independently measured variables (Fig. 2). Although the relationships were quite variable within and among experiments, 95\% confidence limits for regression equations for each of the individual experiments included the origin $(y$-intercept $=0$ ) and a slope of 1.0. Moreover, the slope of the combined data set (0.978) was close to unity indicating a near 1:1 relationship, on average, between sample dilution and the resulting measure of relative grazing activity. It should be clear from this presentation that the measurement of relative grazing activity involves a high level of variability, be it analytical or due to real

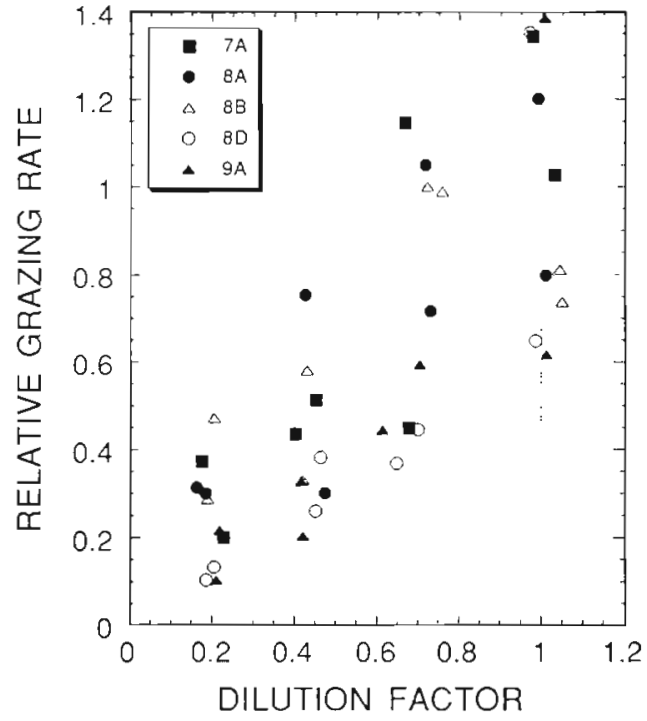

Fig. 2. Relationship between experimentally measured relative grazing rate and dilution factor for 5 experiments in the equatorial Pacific. Dilution factor determined by flow cytometric analysis of Prochlorococcus spp. populations at the start of each experiment relative to undiluted samples. Relative grazing determined from flow cytometric analyses of the decline in fluorescently labeled bacteria tracer cells over the $24 \mathrm{~h}$ incubation period. The combined data is defined by $y=0.032+0.978 x_{i} \Gamma^{2}=0.605$

grazing differences among replicated treatments. For the 10 measurements made in bottles diluted to $70 \%$ natural density, for instance, relative grazing estimates ranged from 0.2 to 1.3 times the estimates from incubations of undiluted water. In contrast, $D_{i}$ appeared to be easily controlled within relatively narrow limits (even including FCM analytical error in making these determinations).

In spite of the broad scatter in relative grazing estimates, the appearance of regression plots were remarkably similar for experiments and populations analyzed by the 2 techniques (Figs. $3 \& 4$ ). There are some differences, of course, in the way that individual data sets conform to best-fit regressions. Nonetheless, all of the relationships were significant at $p \leq 0.05$ ( $6 \mathrm{df}$ ), and the correlation coefficients for the relative grazing regressions were as high on average as the coefficients for the standard dilution analyses (Table 2). Moreover, growth and mortality estimates from the 2 analytical approaches were generally quite comparable for a given experiment (Fig. 5). Growth rate estimates, both with $\left(\mu_{n}\right)$ and without $\left(\mu_{0}\right)$ added nutrients, were particularly well correlated, with slopes that were not significantly different from 1.0 (Fig. 5). The lower correlation coefficient and slope $(<1.0)$ for mortality estimates resulted from the compressed scale of data in these experiments and 2 high estimates $\left(>1.0 \mathrm{~d}^{-1}\right)$ from the standard dilution approach. The remaining data 

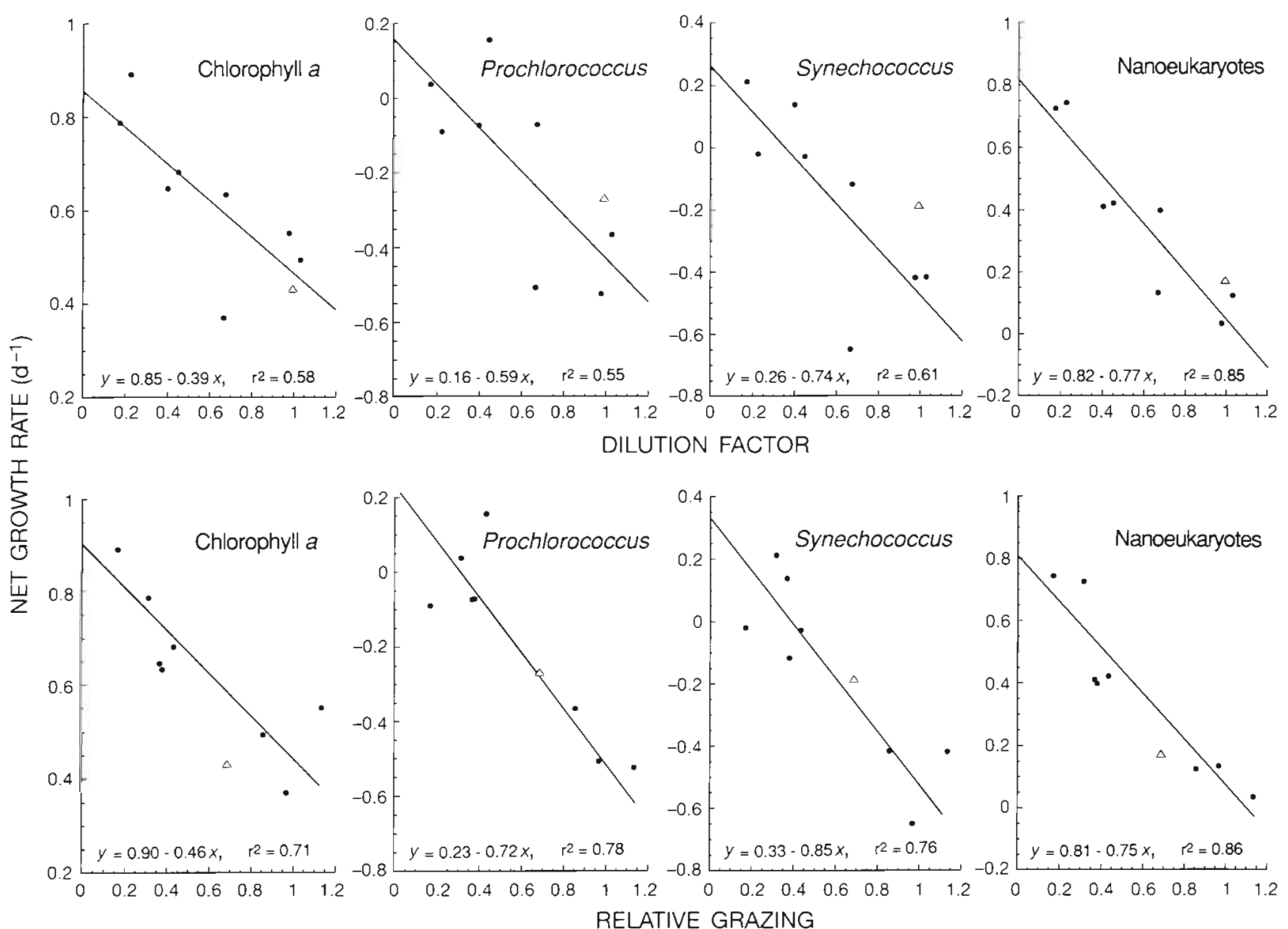

Fig. 3. Analyses of dilution Expt $7 \mathrm{~A}\left(1^{\circ} \mathrm{N}, 140^{\circ} \mathrm{W} ; 10 \mathrm{~m}\right.$ depth) by standard 'dilution factor' and 'relative grazing' (Model II) approaches. Total chlorophyll from fluorometric analyses. Prochlorococcus spp., Synechococcus spp. and nanoeukaryote populations from flow cytometric analyses. Symbols as in Fig. 1

conformed adequately to a $1: 1$ line drawn through the origin (Fig. 5).

Even in cases where the correlation coefficients were high, rate estimates from individual dilution experiments were associated with broad confidence limits (Table 2). Uncertainties in growth rate estimate, for example, averaged $\pm 0.2 \mathrm{~d}^{-1}$ for the dilution factor regressions and $\pm 0.4 \mathrm{~d}^{-1}$ for the relative grazing regressions. Uncertainties in mortality rate estimates averaged $\pm 0.3 \mathrm{~d}^{-1}$ for both approaches. Confidence limits for rate estimates from the 2 regression techniques overlapped broadly and yielded no significant differences in the results of individual experiments.

Mean rate estimates from the 5 experiments showed strong agreement for the 2 analytical approaches (Table 3 ). The relative grazing technique gave estimates that were slightly lower than dilution factor rates in all cases, but the difference did not exceed $0.06 \mathrm{~d}^{-1}$ for any comparison. Growth rate estimates were highest for total chlorophyll $\left(0.87\right.$ to $\left.0.92 \mathrm{~d}^{-1}\right)$ and lowest for Prochlorococcus spp. (0.22 to $\left.0.26 \mathrm{~d}^{-1}\right)$. Growth rates of Synechococcus spp. and nanoeukaryotes were in the vicinity of 1 cell division $\mathrm{d}^{-1}(0.57$ to $0.61 \mathrm{~d}^{-1}$ and 0.73 to $0.79 \mathrm{~d}^{-1}$, respectively). Only the growth of Synechococcus spp. appeared as if it may have been affected by nutrient availability. However, the rate was slightly higher without nutrients (i.e. inconsistent with nutrient limitation), and the difference between bottles with and without nutrients was not statistically significant.

Rate estimates for grazing mortality were lowest for chlorophyll. Consequently, the difference between growth and grazing mortality was highest for chlorophyll, leaving uncontrolled growth of about one-half cell division $\mathrm{d}^{-1}$. Grazing mortality exceeded the growth estimates for Prochlorococcus spp. by a factor of 3. Growth and grazing mortality for Synechococcus spp. and nanoeukaryotes, in contrast, were more or less in balance. 

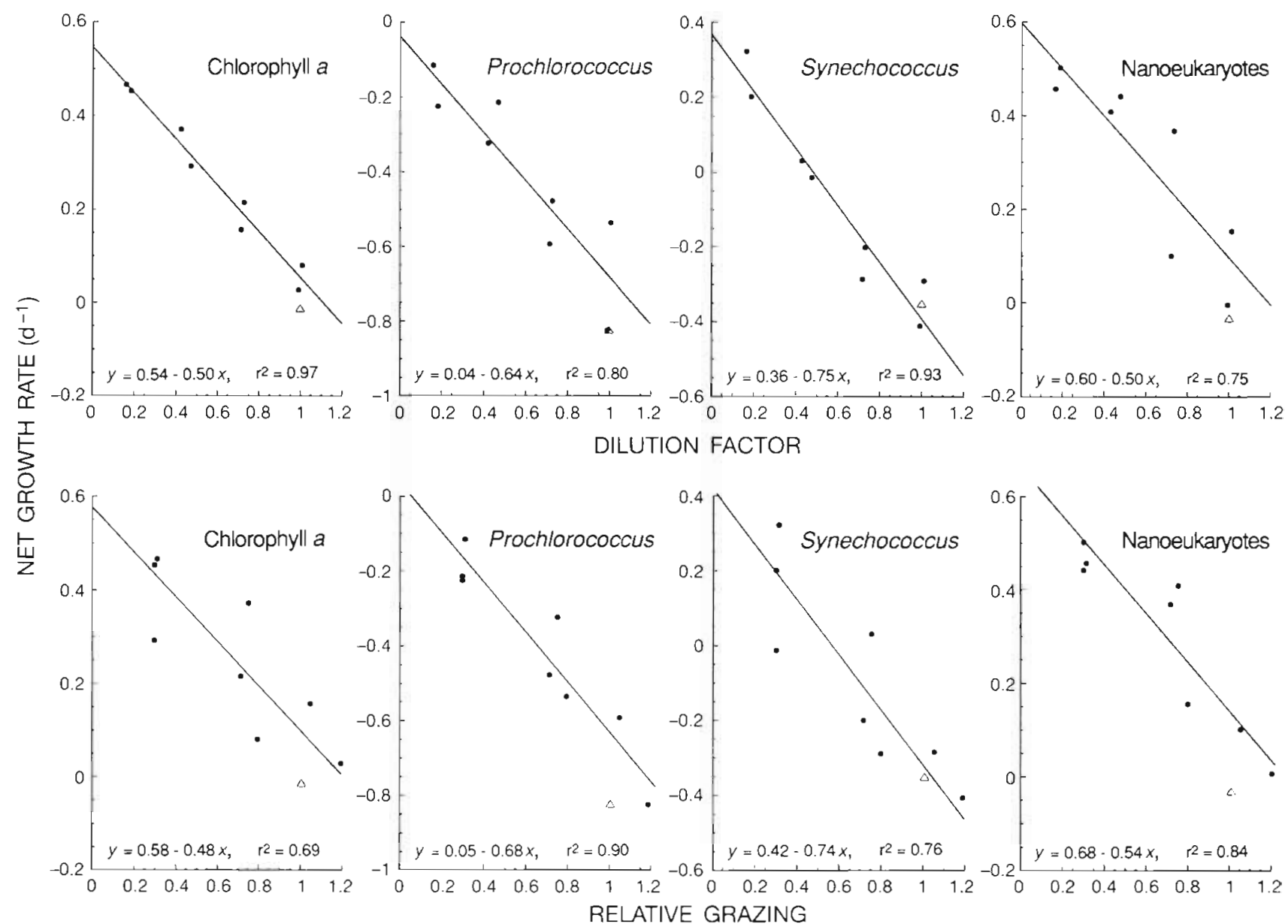

Fig. 4. Analyses of dilution Expt $8 \mathrm{~A}\left(0^{\circ}, 140^{\circ} \mathrm{W} ; 10 \mathrm{~m}\right.$ depth) by standard 'dilution factor' and 'relative grazing' (Model II) approaches. Total chlorophyll from fluorometric analyses. Prochlorococcus spp., Synechococcus spp. and nanoeukaryote populations from flow cytometric analyses. Symbols as in Fig. 1

The mean rate of FLB disappearance in incubation bottles with undiluted seawater was $0.53 \mathrm{~d}^{-1}(\mathrm{SD}=0.28$; $n=20$ ), slightly less than the mortality rate estimates for the individual categories of natural prey analyzed. This lower rate, which amounts to about a $20 \%$ reduction in grazing mortality relative to the mean rates for Prochlorococcus spp., Synechococcus spp., and nanoeukaryote populations, probably reflects a slight tendency of microzooplankton to select for living prey over FLB (e.g. Landry et al. 1991). However, this apparent 'selectivity' does not necessarily imply an active discriminatory mechanism on the part of the microzooplankton; it could result from passive differences in encounter frequencies due to slight prey differences in physical characteristics, motility and cell surface chemistry (e.g. Monger \& Landry 1990, 1992, Gonzales et al. 1993). Comparison of grazing rates on FLB versus mortality rates of comparably sized Synechococcus spp. in the same incubation bottles does not suggest that the consumers alter their feeding behaviors on the FLB tracers relative to natural prey as a function of dilution treatment (Fig. 6).

\section{DISCUSSION}

As part of recent efforts to better understand the dynamics of aquatic microbial communities, a number of observational and experimental approaches have been developed for assessing the grazing impacts of the tiny consumers comprising, broadly, the microzooplankton (see detailed review in Landry 1994). However, none of these methods has emerged as the definitive approach against which all others must be measured. Indeed, the unique strengths of each of the methods are offset by weaknesses which limit applications to specific groups of target organisms or to certain environmental circumstances. 
Table 2. Comparison of phytoplankton growth $(\mu)$ and microplankton grazing $(m)$ estimates from alternative approaches to regression analyses of dilution experiments. Dilution factor: standard Model I regression of net growth rate aganst dilution factor Relative grazing: Model II regression of net growth rate against an independent estimate (fluorescently labeled bacteria disappearance rate) of relative grazing activity. Parentheses give $95 \%$ confidence limits of rate estimates

\begin{tabular}{|c|c|c|c|c|c|c|}
\hline \multirow{2}{*}{ Expt } & \multicolumn{3}{|c|}{ Dilution factor } & \multicolumn{3}{|c|}{ Relative grazing } \\
\hline & $\mu\left(\mathrm{d}^{-1}\right)$ & $m\left(\mathrm{~d}^{-1}\right)$ & $r^{2}$ & $\mu\left(\mathrm{d}^{-1}\right)$ & $m\left(\mathrm{~d}^{-1}\right)$ & $r^{2}$ \\
\hline & \multicolumn{6}{|c|}{ Total chlorophyll } \\
\hline $7 \mathrm{~A}$ & $0.86(0.64,1.07)$ & $0.39(0.06,0.72)$ & 0.58 & $0.90(0.60,1.20)$ & $0.46(0.28,0.77)$ & 0.71 \\
\hline $8 \mathrm{~A}$ & $0.55(0.49,0.61)$ & $0.50(0.41,0.58)$ & 0.97 & $0.58(0.26,0.90)$ & $0.48(0.28,0.81)$ & 0.69 \\
\hline $8 \mathrm{~B}$ & $0.87(0.79,0.95)$ & $0.41(0.29,0.53)$ & 0.92 & $0.96(0.66,1.27)$ & $0.41(0.22,0.75)$ & 0.59 \\
\hline $8 \mathrm{D}$ & $1.13(1.05,1.22)$ & $0.57(0.44,0.70\}$ & 0.95 & $0.99(0.68,1.30)$ & $0.44(0.26,0.73)$ & 0.72 \\
\hline \multirow[t]{2}{*}{$9 \mathrm{~A}$} & $1.00(0.65,1.35)$ & $0.87(0.32,1.41)$ & 0.72 & $0.78(0.23,1.33)$ & $0.74(0.60,0.91)$ & 0.96 \\
\hline & \multicolumn{6}{|c|}{ Prochlorococcus spp. } \\
\hline $7 \mathrm{~A}$ & $0.16(-0.19,0.51)$ & $0.59(0.06,1.12)$ & 0.55 & $0.23(-0.22,0.69)$ & $0.72(0.46,1.12)$ & 0.78 \\
\hline $8 \mathrm{~A}$ & $-0.04(-0.25,0.17)$ & $0.64(0.33,0.96)$ & 0.80 & $-0.05(-0.38,0.47)$ & $0.68(0.49,0.93)$ & 0.90 \\
\hline $8 B$ & $0.49(0.37,0.61)$ & $0.51(0.33,0.69)$ & 0.89 & $0.62(0.23,1.01)$ & $0.52(0.28,0.96)$ & 0.57 \\
\hline $8 \mathrm{D}$ & $0.51(0.35,0.68)$ & $1.03(0.78,1.28)$ & 0.94 & $0.26(-0.31,0.83)$ & $0.80(0.51,1.25)$ & 0.79 \\
\hline \multirow[t]{2}{*}{$9 \mathrm{~A}$} & $0.23(-0.09,0.56)$ & $0.86(0.35,1.37)$ & 0.74 & $0.01(-0.52,0.54)$ & $0.72(0.43,1.21)$ & 0.70 \\
\hline & \multicolumn{6}{|c|}{ Synechococcus spp. } \\
\hline $7 \mathrm{~A}$ & $0.26(-0.12,0.65)$ & $0.74(0.15,1.33)$ & 0.61 & $0.33(-0.22,0.88)$ & $0.85(0.53,1.37)$ & 0.76 \\
\hline $8 \mathrm{~A}$ & $0.36(0.23,0.50)$ & $0.75(0.55,0.96)$ & 0.93 & $0.42(-0.06,0.90)$ & $0.74(0.46,1.19)$ & 0.76 \\
\hline $8 B$ & $0.65(0.47,0.83)$ & $0.52(0.26,0.78)$ & 0.80 & $0.80(0.44,1.17)$ & $0.55(0.39,0.79)$ & 0.87 \\
\hline $8 \mathrm{D}$ & $0.60(0.40,0.79)$ & $0.70(0.40,1.00)$ & 0.84 & $0.44(0.03,0.85)$ & $0.57(0.45,0.73)$ & 0.94 \\
\hline \multirow[t]{2}{*}{$9 \mathrm{~A}$} & $0.50(0.14,0.87)$ & $1.08(0.51,1.66)$ & 0.78 & $0.22(-0.44,0.87)$ & $0.88(0.76,1.03)$ & 0.98 \\
\hline & \multicolumn{6}{|c|}{ Nanoeukaryotes } \\
\hline $7 \mathrm{~A}$ & $0.82(0.61,1.03)$ & $0.77(0.45,1.09)$ & 0.85 & $0.81(0.33,1.28)$ & $0.75(0.52,1.09)$ & 0.86 \\
\hline $8 \mathrm{~A}$ & $0.60(0.41,0.79)$ & $0.50(0.22,0.79)$ & 0.75 & $0.67(0.33,1.02)$ & $0.54(0.37,0.81)$ & 0.84 \\
\hline $8 \mathrm{~B}$ & $0.78(0.72,0.84)$ & $0.39(0.30,0.47)$ & 0.95 & $0.87(0.59,1.14)$ & $0.38(0.21,0.67)$ & 0.64 \\
\hline $8 \mathrm{D}$ & $1.10(0.90,1.30)$ & $0.70(0.38,1.01)$ & 0.83 & $0.94(0.53,1.35)$ & $0.57(0.37,0.88)$ & 0.80 \\
\hline $9 A$ & $0.75(0.38,1.12)$ & $0.74(0.16,1.32)$ & 0.62 & $0.58(0.08,1.07)$ & $0.68(0.42,1.10)$ & 0.74 \\
\hline
\end{tabular}

GROWTH RATE (NUTRIENTS)

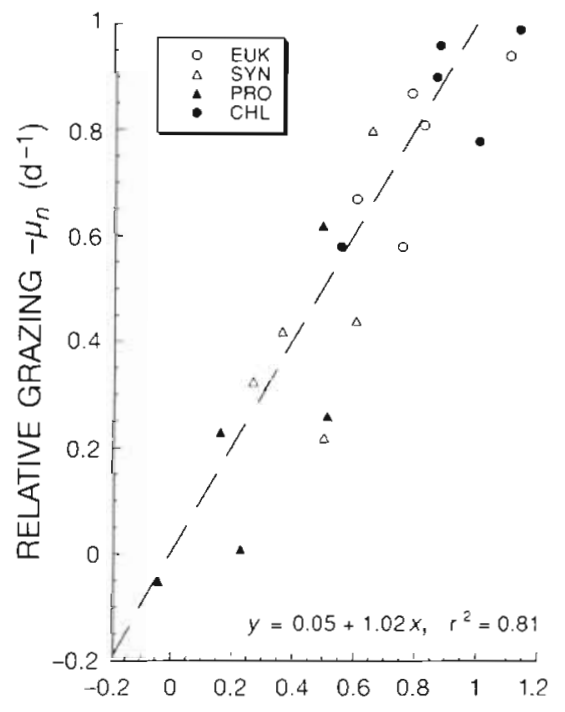

DILUTION FACTOR $-\mu_{n}\left(\mathrm{~d}^{-1}\right)$
GROWTH RATE (NO NUTRIENTS)

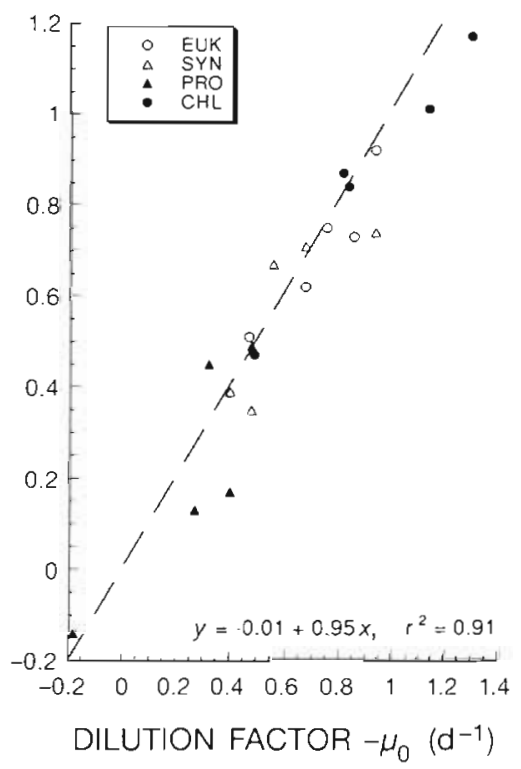

GRAZING MORTALITY

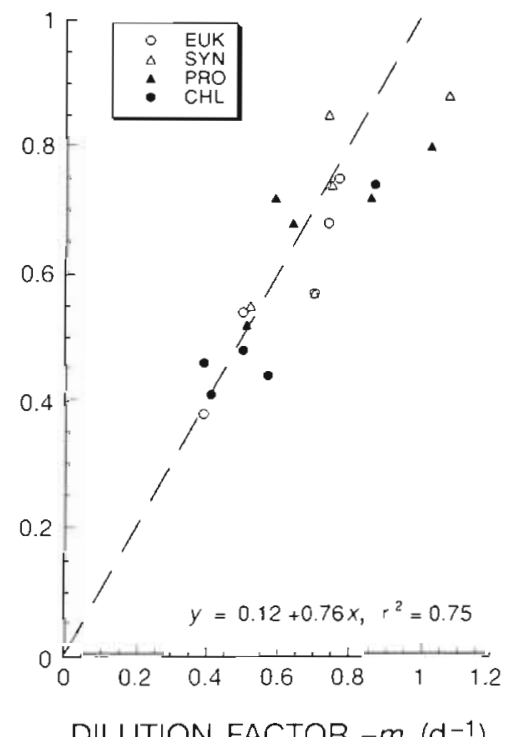

Fig. 5. Relationships between rate estimates from standard 'dilution factor' and 'relative grazing' analyses of dilution experıments in the equatorial Pacific. (- _ - ) 1:1 relationships drawn through the origin. Linear regression analyses based on Model II (geometric mean, reduced major axis) theory 
Table 3. Comparison of mean rate estimates for phytoplankton growth $\left(\mu_{n}, \mu_{0}\right)$ and microzooplankton grazing $(m)$. Dilution factor and Relative grazing as in Table $2 . \mu_{n}$ : growth rate in presence of added nutrients; $\mu_{0}$ : calculated growth rate in control incubations without nutrients. SD for mean rate estimates in parentheses

\begin{tabular}{|lcccccc|}
\hline Parameter & \multicolumn{3}{c}{ Dilution factor } & \multicolumn{2}{c|}{ Relative grazing } \\
& $\mu_{n}$ & $\mu_{0}$ & $m$ & $\mu_{n}$ & $\mu_{0}$ \\
\hline Chlorophyll & $0.88(0.22)$ & $0.92(0.31)$ & $0.55(0.19)$ & $0.84(0.17)$ & $0.87(0.26)$ & $0.51(0.13)$ \\
Prochlorococcus spp. & $0.27(0.23)$ & $0.26(0.26)$ & $0.73(0.21)$ & $0.21(0.26)$ & $0.22(0.26)$ & $0.69(0.10)$ \\
Synechococcus spp. & $0.47(0.16)$ & $0.61(0.21)$ & $0.76(0.20)$ & $0.44(0.22)$ & $0.57(0.19)$ & $0.72(0.15)$ \\
Nanoeukaryotes & $0.81(0.18)$ & $0.79(0.20)$ & $0.62(0.17)$ & $0.77(0.15)$ & $0.73(0.15)$ & $0.58(0.14)$ \\
\hline
\end{tabular}

Thus, until perfect methods can be developed, the challenge is to use existing methodologies in such a way that their respective strengths are emphasized and their weaknesses mitigated or at least minimized.

The experimental design described here is a hybrid of 2 existing methodologies - the dilution technique (Landry \& Hassett 1982) and the FLB tracer method (Sherr et al. 1987). The main strength of the dilution technique is its ability to provide growth and grazing estimates in a single experiment for the entire autotrophic assemblage (total chlorophyll) and/or for any of the individual populations that can be dis-

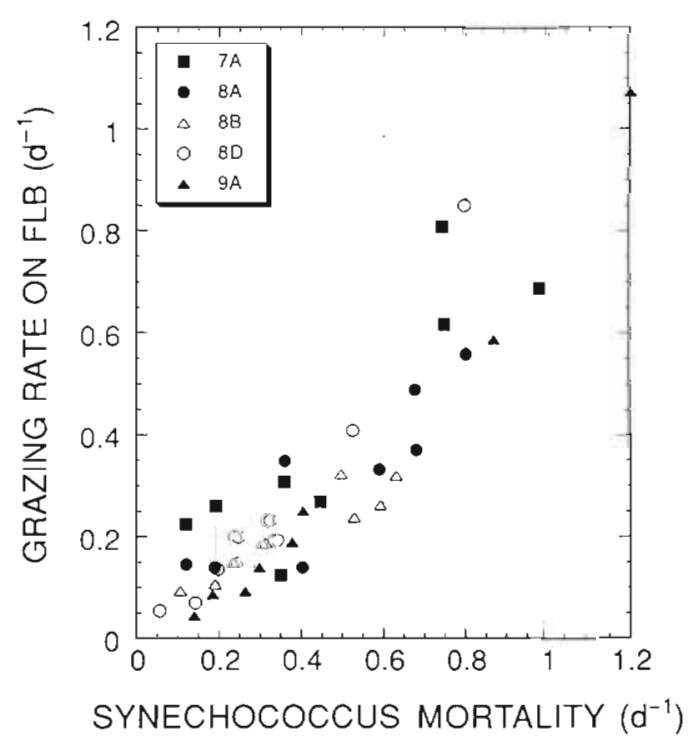

Fig. 6. Relationship between measured grazing rates on fluorescently labeled bacteria $(1.1 \mu \mathrm{m}$ diameter Vibrio damsella) and mortality rate of comparably sized Synechococcus spp, in 5 dilution experiments in the equatorial Pacific. FLB grazing rates were determined from the difference between initial and final FLB densities in each of the dilution treatments. Synechococcus spp. mortality rates were estimated by applying the experimental estimates of Synechococcus spp. growth rate from the dilution regression analyses to the net growth rates observed in each of the dilution treatments. The combined data set is defined by $y=-0.042+0.798 x$;

$$
r^{2}=0.82
$$

tinguished by optical (microscopy, flow cytometry) or taxa-specific chemical (HPLC) characteristics. As noted previously, however, the dilution technique involves a significant experimental manipulation of the community and relatively long incubations over which the growth and grazing assumptions of the method may not hold. The FLB approach, on the other hand, can give an unambiguous indication of grazing activity over short- (uptake into feeding vacuoles) or long-term (cell disappearance) incubations. The main problem with FLB (or FLA) is that the surrogate prey may be selected for or against by protistan consumers. In the present experiments, for example, selection against FLB apparently results in mean grazing rates on the fluorescent tracer about $20 \%$ lower than grazing estimates on comparably sized natural prey (Fig. 6). Thus, the FLB can generally provide only a relative measure of grazing on the natural prey which they are designed to mimic. Moreover, the requirement that fluorescently labeled cells be used in tracer concentrations can severely restrict their use in short-term experiments, particularly in environments such as the open oceans where natural prey concentrations are low (McManus \& Okubo 1991).

The dilutions and FLB methods complement one another in the present experimental design. The FLB method is used in a manner consistent with its strengths - at tracer concentration and as a relative index of grazing activity. In the context of our hybrid experimental design, this grazing index provides a time-integrated measure of the combined effect of dilution on micrograzer population densities and individual clearance rates. A critical assumption of the dilution technique is, thus, replaced by a measured rate. Confidence limits on growth and grazing estimates for natural populations are not necessarily improved by adding this experimental variable; in fact, they may be a little bit worse on average (e.g. Table 2 ). The new experimental design does, however, allow the dilution technique to be applied with greater confidence.

We agree in principle with the criticism of Evans \& Paranjape (1992) that many different interpretations of 
dilution-derived rate estimates are possible if, as seems likely, the functional response curves of micrograzers are nonlinear. We were, therefore, surprised to find that rate estimates from standard dilution experiments in the equatorial Pacific were essentially identical to those from the relative grazing approach, which avoids this controversial assumption. This agreement could mean that the standard dilution interpretation is generally more robust than assumed by Evans and Paranjape (1992) and/or that the central equatorial Pacific is somehow special or atypical relative to other environments in which the technique is applied. With regard to the former explanation, it should be noted that the mortality rate of prey populations depends on both the average clearance rate of individual consumers $(\bar{F})$ and mean consumer density $(\bar{P})$ during the incubation period (i.e. $m=\bar{F} \times \bar{P}$ ). If the functional response is nonlinear and uncomplicated by feeding thresholds within the dilution range, individual clearance rates will likely increase with dilution of prey concentration (e.g. Fenchel 1986). On the other hand, dilution effects on food level and predators also lead to differences among dilution treatments in the growth and mortality rates of consumer populations during the incubation. If the net effect of dilution is a slower growth rate of consumers, an increase in clearance rate could be balanced, all or in part, by reduced or negative population growth rate in diluted relative to undiluted samples. In such cases, the combined manipulation effects on clearance rate ind. ${ }^{-1}$ and grazer density could produce mortality rates which vary approximately linearly with dilution.

If not atypical, the central equatorial Pacific is at least an optimal environment in many respects for applications of the dilution technique. The autotrophic plankton community is strongly dominated by small cells (Prochlorococcus spp., Synechococcus spp., and tiny eukaryotes) which can be adequately modeled by coccoid FLB of intermediate size. From 80 to $90 \%$ of chlorophyll passes through a $2 \mu \mathrm{m}$ filter (R. Bidigare pers. comm.). Cell concentrations are characteristic of oceanic levels and unlikely to be above levels that saturate grazer ingestion rates (e.g. Gallegos 1989). Macronutrients are present in high concentrations, and the comparable growth rates of autotrophs with and without added nutrients give no indication of nutrient limitation effects during $24 \mathrm{~h}$ incubations. The fact that the standard dilution and the relative grazing approaches agree so closely under such circumstances is no guarantee that they would or should under more difficult, and perhaps more typical, circumstances. This remains to be seen in future applications of the modified experimental technique.

The main point of this paper is that the standard dilution approach to estimating rates of phytoplankton growth and grazing mortality need not be applied blindly. It may take some imagination to come up with appropriate tracer models of the dominant phytoplankton in some environments and to measure their relative losses to grazing with enough precision to yield significant results in the new relative grazing/ dilution approach. If these potential technical problems can be overcome, however, the new hybrid approach will, at worst, allow us to understand the circumstances under which the standard dilution approach can be applied in a manner consistent with its assumptions. At best, the new technique will be able to provide unbiased estimates of growth and grazing rates even when conditions violate the assumptions of the standard dilution protocol.

Acknowledgements. The authors gratefully acknowledge EQPAC coordinator J. Murray, Chief Scientist R. Barber, and the captain and crew of the RV 'Thomas G. Thompson' for their efforts in coordinating and facilitating the shipboard research program. We also thank $\mathrm{R}$. Letelier and $\mathrm{E}$. Laws for advice on statistical analyses, $K$. Parayno for preparing the text and tables, and $G$. Evans and 2 anonymous reviewers for helpful comments on the manuscript. This research was supported by National Science Foundation Grants OCE 90-22117 and 93-15432. Contribution No. 3859 from the School of Ocean and Earth Science and Technology, University of Hawaii at Manoa. JGOFS contribution No. 194

\section{LITERATURE CITED}

Andersen, T., Schartau, A. K. L., Paasche, E. (1991). Quantifying external and internal nitrogen and phosphorous pools, as well as nitrogen and phosphorus supplied through remineralization, in coastal marine plankton by means of a dilution technique. Mar. Ecol. Prog. Ser. 69: 67-80

Burkill, P. H., Mantoura, R. F. C., Llewellyn, C. A., Owens, N. J. P. (1987). Microzooplankton grazing and selectivity of phytoplankton in coastal waters. Mar. Biol. 93: 581-590

Campbell, L., Carpenter, E. J. (1986). Estimating the grazing pressure of heterotrophic nanoplankton on Synechococcus spp. using the sea water dilution and selective inhibitor techniques. Mar. Ecol. Prog. Ser. 33: 121-129

Chavez, F. P., Buck, K. R., Coale, K. H., Martin, J. H., DiTullio, G. R., Welschmeyer, N. A., Jacobson, A. C., Barber, R. T (1991). Growth rates, grazing, sinking, and iron limitation of equatorial Pacific phytoplankton. Limnol. Oceanogr. 36: $1816-1833$

Evans, G. T., Paranjape, M. A. (1992). Precision of estimates of phytoplankton growth and microzooplankton grazing when the functional response of grazers may be nonlinear Mar. Ecol. Prog. Ser. 80: 285-290

Fenchel, T (1986). Protozoan filter feeding. Prog. Protistol. 1. $65-113$

Fitzwater, S. E., Knauer, G. A., Martin, J. H. (1982). Metal contamination and its effect on primary production measurements. Limnol. Oceanogr. 27:544-551

Fuhrman, J. A., Bell, T. M. (1985). Biological considerations in the measurement of dissolved free amino acids in seawater and implications for chemical and microbiological studies. Mar. Ecol. Prog. Ser. 25: 13-21

Gallegos, C. L. (1989). Microzooplankton grazing on phytoplankton in the Rhode River, Maryland: nonlinear feeding 
kinetics. Mar. Ecol. Prog. Ser. 57: 23-33

Gifford, D. J. (1988). Impact of grazing by microzooplankton in the Northwest Arm of Halifax Harbour, Nova Scotia. Mar. Ecol. Prog. Ser. 47: 249-258

Gonzales, J. M., Sherr E.B., Sherr, B. F. (1993). Differential feeding by marine flagellates on growing versus starving, and on motile versus non-motile, bacterial prey. Mar. Ecol. Prog. Ser. 102: 257-267

Jolicoeur, P., Mosimann, J. E. (1968). Intervalles de confiance pour la pente de l'axe majeur d'une distribution normale bidimensionnelle. Biom.-Praxim. 9: 121-140

Landry, M. R. (1993). Estimating rates of growth and grazing mortality of photoautotrophic plankton by dilution. In. Kemp, P. F., Sherr, B. F., Sherr, E. B., Cole, J. J. (eds.) Handbook of methods in aquatic microbial ecology. Lewis Publishers, Boca Raton, FL, p. 715-722

Landry, M. R. (1994). Methods and controls for measuring the grazing impact of planktonic protists. Mar. microb. Food Webs 8: $37-57$

Landry, M. R., Haas, L. W., Fagerness, V. L. (1984). Dynamics of microbial plankton communities: experiments in Kaneohe Bay, Hawaii. Mar. Ecol. Prog. Ser 16: 127-133

Landry, M. R., Hassett, R. P. (1982). Estimating the grazing impact of marine micro-zooplankton. Mar. Biol. 67: 283-288

Landry, M. R., Lehner-Fournier, J. M., Sundstrom, J. A., Fagerness, V. L., Selph, K. E. (1991). Discrimination between living and heat-killed prey by a marine zooflagellate, Paraphysomonas vestita. J. exp. mar. Biol. Ecol. 146: 139-151

Landry, M. R., Monger, B. C., Selph, K. E. (1993). Timedependency of microzooplankton grazing and phytoplankton growth in the subarctic Pacific. Prog. Oceanogr. 32: $205-222$

Laws, E. A., Archie, J. W. (1981) Appropriate use of regression analysis in marine biology. Mar. Biol. 65: 13-16

Li, W. K. W. (1990). Particles in 'particle-free' seawater: growth of ultraplankton and implication for dilution experiments. Can. J. Fish. Aquat. Sci. 47: 1258-1268

Li, W. K. W., Dickie, P. M. (1985). Growth of bacteria in seâwater filtered through $0.2 \mu \mathrm{m}$ Nuclepore membranes:

This article was submitted to the editor implications for dilution experiments. Mar. Ecol. Prog. Ser. 26: $245-252$

McManus, G. B., Okubo, A. (1991). On the use of surrogate food particles to measure protistan ingestion Limnol. Oceanogr. 36: 613-617

Monger, B. C., Landry, M. R. (1990). Direct interception feeding by zooflagellates: The importance of surface and hydrodynamic forces. Mar. Ecol. Prog. Ser. 65: 123-140

Monger, B. C., Landry, M. R. (1992). Size-selective grazing by heterotrophic nanoflagellates: an analysis using livestained bacteria and dual-beam flow cytometry. Arch Hydrobiol. Beih. Ergeb. Limnol. 37: 173-184

Monger, B. C., Landry, M. R. (1993). Flow cytometric analysis of marine bacteria with Hoechst 33342. Appl. environ. Microbiol. 59: 905-911

Paranjape, M. A. (1987). Grazing by microzooplankton in the eastern Canadian arctic in summer 1983. Mar. Ecol. Prog Ser. 40:239-246

Paranjape, M. A. (1990). Microzooplankton herbivory on the Grand Bank (Newfoundland, Canada): a seasonal study. Mar. Biol. 107: 321-328

Ricker, W. E. (1973). Linear regressions in fishery research J. Fish. Res. Bd Can. 30: 409-434

Sherr, B. F., Sherr, E. B., Fallon, R. D. (1987). Use of monodispersed, fluorescently-labeled bacteria to estimate in situ protozoan bacterivory. Appl. environ. Microbiol. 53: 958-965

Sokal, R. R., Rohlf, F. J (1969). Biometry. The principles and practice of statistics in biological research. W. H. Freeman \& Co., San Francisco

Strom, S. L., Welschmeyer, N. A. (1991). Pigment-specific rates of phytoplankton growth and microzooplankton grazing in the open subarctic Pacific Ocean. Limnol Oceanogr. 36: 50-63

Weisse, T., Scheffel-Möser, U. (1990). Growth and grazing loss rates in single-celled Phaeocystis sp. (Prymnesiophyscae). Mar. Biol. 106: 153-158

York, D. (1966). Least-squares fitting of a straight line. Can. J. Phys, 44: 1079-1086

Manuscript first received: March 23, 1994

Revised version accepted: January 6, 1995 